\title{
ADOLESCENT GYNAECOLOGICAL PROBLEMS: A PROSPECTIVE STUDY
}

\author{
Prakriti Goswami ${ }^{1}$,Geeta Ahirwar 2 , Prabha Mishra ${ }^{3}$, Veena Agrawal 4
}

${ }_{1}^{1}$ Medical Officer, Department of Obstetrics and Gynaecology, District Hospital, Shivpuri.

${ }_{2}^{2}$ Medical Officer, Department of Obstetrics and Gynaecology, District Hospital, Morar, Gwalior.

${ }^{3} 3^{\text {rd }}$ Year PG Student, Department of Obstetrics and Gynaecology.

${ }^{4}$ Ex-Professor, Department of Obstetrics and Gynaecology, G. R. Medical College, Gwalior.

ABSTRACT
CONTEXT/BACKGROUND
Adolescence, meaning “To grow up," is a transitional stage of physical, sexual and mental human development occurring between
puberty and legal adulthood. The Government of India in National Youth Policy defines adolescents as individuals between 13 to 19
yrs. of age.

\section{AIMS}

To study the magnitude of different adolescent gynecological problems in patients attending OPD of GRMC, Gwalior, MP.

\section{SETTINGS AND DESIGN}

Prospective study in patients attending gynecological OPD of GRMC, Gwalior, MP.

\section{SAMPLE SIZE: 75}

\section{METHODS AND MATERIALS}

Seventy five adolescent girls in the age group of 13-19 yrs. attending gynecological OPD of GRMC, Gwalior, from November 2013 to October 2014 were included in the study. Detailed history, general examinations and investigations were done to evaluate their health.

\section{STATISTICAL ANALYSIS}

Was done using Microsoft Excel.

\section{RESULTS}

Incidence of gynecological problem in our study was 3.33\%. Different gynecological problems were menstrual disorders (60\%), leucorrhoea (10.66\%), infections (8\%), ovarian cyst (5.33\%), sexual assault (2.66\%), teenage pregnancy (10.66\%) and infertility (2.66\%). Majority of girls with menstrual disorders suffered from puberty menorrhagia (55.55\%). Dysfunctional uterine bleeding was diagnosed in $96 \%$ of girls suffering from puberty menorrhagia. Pelvic Inflammatory Disease was exclusively seen in married adolescent girls. Vaginal atresia and imperforate hymen were causes of primary amenorrhoea. PCOD was commonest cause of secondary amenorrhoea amongst adolescents.

\section{CONCLUSION}

Menstrual abnormalities are the most common problems of adolescent girls. Setting up adolescent clinics is desirable.

\section{KEYWORDS}

Adolescence, Gynecological Problems.

HOW TO CITE THIS ARTICLE: Prakriti Goswami, Geeta Ahirwar, Prabha Mishra, Veena Agrawal. "Adolescent Gynaecological Problems: A Prospective Study." Journal of Evolution of Medical and Dental Sciences 2015; Vol. 4, Issue 102, December 21; Page: $16709-16712$, DOI: $10.14260 /$ jemds/2015/2500

\section{INTRODUCTION}

Adolescence is the time period between 10 and 19 years of age.(1),(2) during which along with physiological changes, psychological and socio-behavioral changes also occur.

It is imperative to have a thorough knowledge of the normal changes occurring in this age-group, as also of the demographic pattern of distribution and prevalence of specific gynecological problems in order to offer quality medical/surgical services to this group of patients.

Financial or Other, Competing Interest: None.

Submission 14-12-2015, Peer Review 15-12-2015,

Acceptance 16-12-2015, Published 18-12-2015.

Corresponding Author:

Dr. Prakriti Goswami,

D-12, Gandhi Nagar,

Gwalior,

Madhya Pradesh.

E-mail: goswami.prakriti@gmail.com

DOI:10.14260/jemds/2015/2500
Adolescent girls make up to $10 \%$ of total population and $20 \%$ of female population according to Adolescent population project, 1996.

\section{Adolescence can be divided into three sub phases}

1. Early adolescence (10-14 years): characterized by the onset of puberty and transition out of childhood.

2. Middle adolescence: Identification with group, indicated by wearing of particular clothing, listening to same music, adopting similar verbal phrases.

3. Late adolescence: Transition into adult roles indicated by responsible and mature approach to one's personal and intimate relationships.

Gynecological problems of adolescents occupy a special space in the spectrum of gynecological disorders of all ages. This is because of the physical nature of the problems which are so unique, special and specific for the age group and also because of the associated and psychological factors which are 
very important in the growth and psychological remodeling of someone in the transition between childhood and womanhood. Yet adolescent gynecology is a subspecialized area of Gynecology, which has still not been explored optimally. In this study, an attempt has been made to review the gynecological problems of the adolescent population attending the Gynaecological Outpatient Department (OPD) of GRMC, Gwalior, MP.

\section{METHODS}

\section{Study Design}

Prospective study in patients attending Gynecological OPD of GRMC, Gwalior, MP.

\section{Study Period}

November 2013 to October 2014.

\section{Sample Size: 75 .}

\section{Inclusion Criteria}

Patients attending gynecological OPD of GRMC, Gwalior, above the age of 13 yrs. and up to the age of 19 yrs.

\section{Exclusion Criteria}

Any surgical or medical illness.

After taking approval from Ethical Committee, GRMC, Gwalior, MP, detailed history was taken regarding age at menarche, menstrual and marital history. Detailed history of gynecological problems and other associated problems were taken. A thorough general examination including weight, height and secondary sexual characters was done. Investigations such as haemogram, coagulogram, hormonal assay and pelvic ultrasound were done when indicated.

\section{STATISTICAL ANALYSIS}

Done using Microsoft Excel.

\section{RESULTS}

Of the total 32,400 patients attending gynecological OPD of GRMC, Gwalior, MP from November 2013 to October 2014, 1080 patients (3.33\%) belonged to the adolescent age group, i.e. 13 to 19 yrs. Maximum adolescent girls attending Gynecological OPD had ages in the range of 17 to 19 yrs. i.e. $56 \%$. (Table 1) Majority of adolescent girls were underweight with BMI $<19$ (52 out of 75: 69.33\%) This could be due to poverty and illiteracy prevalent in our country. (Table 2) 10 out of 75 adolescent girls were married (13.33\%), hence more prone to STDs and reproductive tract infections. Adolescent marriages are still prevalent in our country leading to early sexual activity, teenage pregnancy and its complications. (Table 3).

Majority of adolescent girls suffered from menstrual disorders, i.e. 45 out of $75 ; 60 \%$. This was followed by leucorrhoea $(10.66 \%)$, teenage pregnancy $(10.66 \%)$, infections (8\%), ovarian cysts (5.33\%), sexual assault (2.66\%) and infertility (2.66\%). (Table 4) 25 out of $45(55.55 \%)$ adolescent girls with menstrual disorders had Menorrhagia, 8 out of $45(17.7 \%)$ adolescent girls had dysmenorrhoea, 3 out of $45(6.66 \%)$ adolescent girls had primary amenorrhoea, 8 out of $45(17.7 \%)$ adolescent girls had secondary amenorrhoea and only 1 out of $45(2.22 \%)$ adolescent girls had complaints of oligomenorrhoea. (Table 5).

On investigating the causes of menorrhagia, in 24 out of 25 girls (96\%) no cause could be ascertained, i.e. they suffered from Dysfunctional Uterine Bleeding. In 1 out of 25 adolescent girls (4\%), hypothyroidism was seen as the cause of menorrhagia. None of them suffered from any bleeding disorder. (Table 6) On assesing the degree of anaemia amongst adolescent girls suffering from Menorrhagia, 6 out of 25 girls had $\mathrm{Hb}<6.5 \mathrm{gm} \%, 10$ girls had $\mathrm{Hb}$ in the range of $6.5-7.9 \mathrm{gm} \%$ and 9 girls had $\mathrm{Hb}$ in the range of $8-9 \mathrm{gm} \% ; 13$ out of $25(52 \%)$ girls with menorrhagia required blood transfusion along with hormones and haematinics and remaining 12 out of 25 girls $(48 \%)$ required only hormones and haematinics.

Of the 3 adolescent girls with primary amenorrhoea, 2 girls $(66.66 \%)$ had vaginal atresia and 1 girl (33.33\%) had imperforate hymen 8 adolescent girls presented with secondary amenorrhoea; 6 out of 8 girls i.e. $75 \%$ had polycystic ovarian disease, 1 suffered from hypothyroidism and 1 suffered from TB abdomen; 8 adolescent girls presented with leucorrhoea i.e. $10.66 \%$ and were given treatment; 6 adolescent girls presented with infections in OPD pelvic inflammatory diseases was found exclusively in 3 married adolescent girls owing to early sexual activity; 2 unmarried girls presented with UTI; also 1 married adolescent girl presented with Bartholin's abscess/cyst (Table 8).

Physiological cyst of ovary was found in 4 out of 75 adolescent girls (5.33\%). There were no patients with ovarian tumour. Teenage pregnancy was found in 8 out of 75 adolescent girls, i.e. $10.66 \%$. Two married adolescent girls presented with infertility, sexual assault was reported in 2 out of $75(2.66 \%)$ adolescent girls.

\section{DISCUSSIONS}

Adolescents present with myriads of gynecological problems. In the present study it was revealed that amongst patients attending OPD, adolescent age group patients with specific gynecological complaints were about 3.33\%. The lesser incidence in our study could be because adolescent girls are still shy and do not attend regular gynecological OPD.

The present study showed that menstrual disorders were the most common gynecological problems amongst adolescents (60\%), ranging from amenorrhoea to menorrhagia; 25 out of $45(55.55 \%)$ adolescent girls with menstrual disorders had menorrhagia, 8 out of $45(17.7 \%)$ adolescent girls had dysmenorrhoea, 3 out of $45(6.66 \%)$ adolescent girls had primary amenorrhoea, 8 out of $45(17.7 \%)$ adolescent girls had secondary amenorrhoea. Only 1 out of $45(2.22 \%)$ adolescent girls had complaints of oligomenorrhoea. On investigating the causes of menorrhagia amongst adolescent girls, in 24 out of 25 girls (96\%), no cause could be ascertained, i.e. they suffered from dysfunctional uterine bleeding. In 1 out of 25 adolescent girls (4\%), hypothyroidism was seen as the cause of menorrhagia. None of them suffered from any bleeding disorder; 13 out of $25(52 \%)$ girls with menorrhagia were treated with blood transfusion, hormones and haematinics and remaining 12 out of 25 girls (48\%) required only hormones and haematinics.

Menstrual dysfunction affects the majority of adolescents to some degree and is a leading reason for seeking medical advice.(3) The extent of this problem has been graphically illustrated by Parker et al.(4) who looked at the high prevalence of pain, cramps and mood disturbance during menstruation in teenagers. DUB is not only restricted to the adult population, but is more common in adolescents. ${ }^{(5)}$ It may take 2 to 5 years for the complete maturation of hypothalamic pituitary ovarian axis.(6) 
The majority of girls presenting with menorrhagia will have anovulatory cycles and should respond well to the conservative management such as anti-fibrinolytic agents, oral progestogens or the oral contraceptive pill. However, menorrhagia that occurs at the time of the menarche is more likely to be associated with an underlying bleeding disorder.(7) Acute adolescent menorrhagia is associated with a primary coagulation disorder in as many as $20 \%$ of cases.(8) Von Willebrand's disease is the commonest coagulation disorder and a comprehensive haemostatic evaluation is recommended. Treatment with the intrauterine system (Mirena) is an option that is being used increasingly commonly in adolescents and should figure alongside the more traditional approaches.(9)

Goswami Sebanti et al. conducted a study on 124 adolescent girls attending Gynecological OPD and concluded that menstrual disorders were the commonest gynaecological problem $(58.06 \%)$. They varied from amenorrhea (29.16\%) to menorrhagia. Dysfunctional uterine bleeding was the commonest etiology of menstrual dysfunction (32/46) in the group under study.(10)

In the present study, 11 out of 45 girls (24.4\%) presenting with menstrual disturbances had amenorrhoea; 3 girls had primary and 8 girls had secondary amenorrhoea. Of the 3 adolescent girls with primary amenorrhoea, 2 girls (66.66\%) had vaginal atresia and 1 girl (33.33\%) had imperforate hymen. The incidence of primary amennorhoea has been reported in the range of $0.65 \%$ to $83.3 \%$ in different series in the adolescents.(10),(11)

of the 8 adolescent girls presenting with secondary amenorrhoea, 6 of them i.e. $75 \%$ had polycystic ovarian disease, 1 had hypothyroidism and 1 had TB abdomen. Goswami Sebanti et al. in their study found a similar result. In their study, most of the patients (10/13) suffering from secondary amenorrhea (Duration 4-5 months) or oligomenorrhea were ultimately diagnosed to be cases of Polycystic Ovarian Disease (PCOD) based on clinical criteria of menstrual problems, features of hyperandrogenism and sonography findings. ${ }^{(10)}$

In the present study leucorrhoea was found in 8 out of 75 girls, i.e. $10.66 \%$. Leucorrhoea is a frequent and embarrassing problem, especially in low socio-economic population. Leucorrhoea can be physiological or pathological. Increased levels of endogenous estrogen lead to marked overgrowth of the endocervical epithelium, which may encroach outward and produce ectocervical erosion leading to excess discharge. ${ }^{(12)}$

In the present study 6 out of 75 , i.e. $8 \%$ patients presented with infections. Pelvic Inflammatory Disease was seen exclusively in married adolescent girls owing to early sexual activity. Urinary tract infection was seen in 3 of unmarried adolescent girls. Bartholin abscess/cyst was seen in one of the married adolescent girl.

Vulvovaginitis is inflammation of the vulvar and vaginal tissues. Pierce et al. considered poor hygiene as one of the predisposing factors.(13) Jaquiery et al. found no difference in cases and controls in regard to hygiene practices, exposure to irritants or history of child sexual abuse.(14) Cox et al. studied the infectious etiology of vulvovaginitis in young girls and found most common pathogen group A Streptococci in 19 cases and $\mathrm{H}$. influenzae in 11 cases as second most common pathogen.(15)
Physiological cyst of ovary was found in 4 out of 75 adolescent girls (5.33\%), there were no patients with ovarian tumour. Functional cysts are the most frequently observed cystic masses in the ovary accounting for $20-50 \%$ ovarian tumours during childhood and adolescence.(16)

Teenage pregnancy is a common problem in developing countries like India and was seen in $10.66 \%$ of cases in our study. Pregnancy in teenagers is a problem threatening the ultimate reproductive and child health. These girls often do not have safe sex and are vulnerable to sexually transmitted diseases. Moreover after getting pregnant, to avoid social problems, they go to quacks and undergo criminal abortion in unauthorized locations and land up with serious complications and chronic pelvic inflammatory disease, which affect their reproductive health in future.

Teenage pregnancies accounted for $4.03 \%$ of $(5 / 124)$ cases in the study conducted by Goswami Sebanti et al.(10) In the US at least $75 \%$ of adolescent pregnancies are unintended.(17) one-half of which ends in abortion.(18) In a study recently conducted in Banaras Hindu University Institute of Medical Science, teenage pregnancy was found to be associated with a significantly higher risk of PIH, PET and eclampsia, premature onset of labor, fetal deaths and premature delivery. Increased neonatal morbidity and mortality were also seen in babies delivered to teenage mothers. Younger teenager group $(\leq 17$ years) was most vulnerable to adverse obstetric and neonatal outcomes.(19)

Sexual assault was seen in 2 out of $75(2.66 \%)$ of adolescent girls in our study. Sexual assault may lead to lower self-esteem, depression, unwanted pregnancies and criminal abortions amongst adolescents. In a literature survey from the 1980 s, the prevalence of child sexual abuse in the USA was $10 \%-12 \%$. ${ }^{20)}$ Studies in the USA have suggested that approximately $1 \%$ of children experience some form of sexual abuse each year, resulting in the sexual victimization of $12 \%$ $25 \%$ of girls and $8 \%-10 \%$ of boys by age 18 (National study on the incidence of child abuse and neglect, 1988).

\section{CONCLUSION}

Adolescents present with a myriad of gynaecological problems. Menstrual disorders were the commonest gynaecological problems of adolescents. Adolescent gynaecology is not a new subject. But it needs increasing awareness and further attention. Since the problems are specific to this group, setting up of separate adolescent clinics is desirable for efficient management.

\begin{tabular}{|c|c|c|}
\hline Age (In yrs.) & Number & Percentage \\
\hline $13-15$ & 10 & 13.33 \\
\hline $15-17$ & 23 & 30.66 \\
\hline $17-19$ & 42 & 56 \\
\hline \multicolumn{3}{|c|}{ Table 1: Age distribution among } \\
Adolescents attending OPD
\end{tabular}

\begin{tabular}{|c|c|c|}
\hline BMI & Number & Percentage \\
\hline$<19$ - Underweight & 52 & 69.33 \\
\hline $19-25$ - Normal & 15 & 20 \\
\hline $25-30$ - Overweight & 8 & 10.66 \\
\hline$>30$ - Morbid Obesity & 0 & 0 \\
\hline
\end{tabular}

Table 2: Distribution of BMI in outpatient adolescents 


\begin{tabular}{|c|c|c|}
\hline Status & Number & Percentage \\
\hline Unmarried & 65 & 86.66 \\
\hline Married & 10 & 13.33 \\
\hline \multicolumn{2}{|c|}{ Table 3: Marital status of Adolescent Girls } \\
\hline
\end{tabular}

\begin{tabular}{|c|c|c|}
\hline Disorders & Number & Percentage \\
\hline Menstrual disorder & 45 & 60 \\
\hline Leucorrhoea & 8 & 10.66 \\
\hline Infections & 6 & 8 \\
\hline Ovarian cyst & 4 & 5.33 \\
\hline Sexual assault & 2 & 2.66 \\
\hline Teenage pregnancy & 8 & 10.66 \\
\hline Infertility & 2 & 2.66 \\
\hline \multicolumn{2}{|c|}{ Table 4: Gynaecological Problems } \\
amongst Adolescent girls
\end{tabular}

\begin{tabular}{|c|c|c|}
\hline Disorders & Number & Percentage \\
\hline Menorrhagia & 25 & 55.55 \\
\hline Dysmenorrhoea & 8 & 17.7 \\
\hline Oligomenorrhoea & 1 & 2.22 \\
\hline Primary Amenorrhoea & 3 & 6.66 \\
\hline Secondary Amenorrhoea & 8 & 17.77 \\
\hline \multicolumn{2}{|c|}{ Table 5: Menstrual disorders } \\
\hline
\end{tabular}

\begin{tabular}{|c|c|c|}
\hline Cause & Number & Percentage \\
\hline DUB & 24 & 96 \\
\hline Coagulation disorders & - & - \\
\hline Hypothyroidism & 1 & 4 \\
\hline \multicolumn{2}{|c|}{ Table 6: Causes of Menorrhagia } \\
\hline
\end{tabular}

\begin{tabular}{|c|c|c|}
\hline Etiology & Number & Percentage \\
\hline Imperforate hymen & 1 & 33.3 \\
\hline Vaginal agenesis & 2 & 66.6 \\
\hline \multicolumn{2}{|c|}{ Table 7: Etiology of Primary Amenorrhoea } \\
\hline
\end{tabular}

\begin{tabular}{|c|c|c|}
\hline Etiology & Number & Percentage \\
\hline PCOD & 6 & 75 \\
\hline Hypothyroidism & 1 & 12.5 \\
\hline TB abdomen & 1 & 12.5 \\
\hline \multicolumn{2}{|c|}{ Table 8: Etiology of Secondary Amenorrhoea } \\
\hline
\end{tabular}

\begin{tabular}{|c|c|c|c|}
\hline Infections & Married & Unmarried & \% \\
\hline PID & 3 & - & 50 \\
\hline UTI & - & 2 & 33.33 \\
\hline $\begin{array}{c}\text { Bartholin's } \\
\text { abscess/cyst }\end{array}$ & 1 & - & 16.66 \\
\hline \multicolumn{3}{|c|}{ Table 9: Infections amongsts Adolescent girls } \\
\hline
\end{tabular}

\section{REFERENCES}

1. World health Organization; 1998: Proceedings of the WHO South Asia Conference on Adolescence.

2. World Health Organization, Internet: Website of Department of Child and Adolescent Health and Development; (http://www.who.int/child-adolescenthealth) Accessed November 9, 2007.
3. Slap BG. Menstrual disorders in adolescence. Best Pract Res Clin Obstet Gynaecol 2003;17:75-92.

4. Parker MA, Sneddon AE, Arbon P. The Menstrual Disorder of Teenagers (MDOT) Study: determining typical menstrual patterns and menstrual disturbances in a large population-based study of Australian teenagers. BJOG 2010;117:185-92.

5. Sanifileppo J, Yussman M. Gynecological problems of adolescene. In: Lavery J, Snifileppo J. (eds). Pediatric and Adolescent Gynecology New York. Springer - Verlag, 1985;61-3.

6. Falcone T, Desjardins C, Bourque J, et al. Dysfunctional uterine bleeding in adolescents. J Reprod Med 1994;39:7761:4.

7. Bevan JA, Maloney KW, Hillery CA, et al. Bleeding disorders: a common cause for menorrhagia in adolescents. J Pediatr 2001;138:856-61.

8. Claessens EA, Cowell CA. Acute adolescent menorrhagia. Am J Obstet Gynaecol 1981;139:277-80.

9. Pillai M, O’Brien K, Hill E. The levonorgestrel intrauterine system (Mirena) for the treatment of menstrual problems in adolescents with medical disorders or physical or learning disabilities. BJOG 2010;117:216-21.

10. Goswami S, Dutta R, Sengupta S. A profile of adolescent girls with gynaecological problems; Journal of Obstetrics and Gynaecology of India; 55:4:353-355.

11. Radhwanska E, Dwyer GM: Journal of Obs. Gynaec, British Commonwealth; 81:107; 1974.

12. Datta DC, Konar H. Textbook of Gynaecology; Kolkata, India: Central, 2007:504.

13. Pierce AM, Hart CA (1992): Vulvovaginitis: causes and management. Arch Dis Child 67:509-12.

14. Jaquiery A, Stylianopoulos A, Hogg G, et al. (1999): Vulvovaginitis: clinical features, aetiology and microbiology of the genital tract. Arch Dis Child 81:6467.

15. Cox RA (1997): Haemophilus influenza: an underrated cause of vulvovaginitis in young girls. J Clin Pathol 50:765-68.

16. Kozlowski KJ (1999): Ovarian masses. Adolesc Med 10:337-50.

17. Henshaw SK.: Unintended pregnancy in the United States. Family planning perspectives: 30:24-29; 1998.

18. Teen sex and pregnancy (fact-sheet) New York: The Alan Guttmatter Institute; 1999.

19. Kumar A, Singh T, Basu S, et al.: Outcome of teenage pregnancy; Indian Journal of Pediatrics: 74.10:927-931; 2007.

20. Feldman W, Feldman E, Goodman JT, McGrath PJ, Pless RP, Corsini L, et al. (1991): Is childhood sexual abuse really increasing in prevalence? An analysis of the evidence. Pediatrics 88:29-33. 